\title{
Guideline for Electricity Generation from Hot Springs (Natural Energy Storage Systems): A Techno-enviro-economic Assessment
}

\author{
Saeed Ghoddousi*1, Behnaz Rezaie ${ }^{1}$, Samane Ghandehariun ${ }^{2}$ \\ ${ }^{1}$ Applied Energy Research Laboratory (AERL), Department of Mechanical Engineering, College \\ of Engineering, University of Idaho 875 Perimeter Dr., Moscow, ID 83844-0902, \\ ${ }^{2}$ Sustainable Energy Research Group (SERG), School of Mechanical Engineering, Iran \\ University of Science and Technology, Narmak, Tehran, Iran \\ Ghod4080@vandals.uidaho.edu; Rezaie@uidaho.edu; Samane_ghandehariun@iust.ac.ir
}

\begin{abstract}
The scattered hot springs on the globe are natural thermal energy storages that are available for industrial and recreational advantages. A hot spring is a hydrothermal system that can be used for power generation purposes as well as deep-well geothermal plants. In the present study, a techno-enviro-economic study is conducted to determine the power generation potential of hot springs as a heat source of the Organic Rankine Cycle (ORC). The hot water temperature and discharge mass flow rate from hot springs varies from 60 to $90{ }^{\circ} \mathrm{C}$ and 5 to $50 \mathrm{~kg} / \mathrm{s}$, respectively. The ORC plant is modeled by Aspen Plus V9. The impacts of the temperature and mass flow rate of discharge from hot springs on the thermodynamics and economics of the plants are investigated. The results indicate that increasing the hot spring temperature and discharge mass flow rate improves the thermal efficiency and power generation capacity of ORC plant while Payback Period (PP), Levelized Energy Cost (LEC), and Specific Investment Cost (SIC) shrink. The power generation capacity varies from $9.3 \mathrm{~kW}$ to $303 \mathrm{~kW}$ and the LEC range is from $0.03 \$ / \mathrm{kWh}$ to $0.13 \$ / \mathrm{kWh}$ based on the hot spring and water discharge mass flow rate.
\end{abstract}

Keywords: Geothermal energy; Natural energy storage; Hot spring energy plant; Techno-enviro-economic assessment; ORC; Power generation

\begin{tabular}{|ll|}
\hline Nomenclature & \\
$\dot{m}$ & Mass flow rate $(\mathrm{kg} / \mathrm{s})$ \\
$\dot{Q}$ & Heat transfer crossing the component boundaries $(\mathrm{kW})$ \\
$\dot{W}$ & Work transfer crossing the component boundaries $(\mathrm{kW})$ \\
$\mathrm{h}$ & Specific enthalpy $(\mathrm{kJ} / \mathrm{kg})$ \\
$\mathrm{V}$ & Stream velocity $(\mathrm{m} / \mathrm{s})$ \\
$\mathrm{z}$ & Stream elevation $(\mathrm{m})$ \\
$\mathrm{g}$ & Acceleration of gravity $\left(\mathrm{m} / \mathrm{s}^{2}\right)$ \\
$\mathrm{T}$ & Temperature $\left({ }^{\circ} \mathrm{C}\right)$ \\
$\mathrm{A}$ & Area $\left(\mathrm{m}^{2}\right)$ \\
$\mathrm{C}$ & Cost $(\$)$ \\
$\mathrm{t}_{\mathrm{op}}$ & The operation hours in a year $(\mathrm{h})$ \\
$\mathrm{N}$ & lifetime $($ year $)$ \\
$\mathrm{P}_{\mathrm{e}}$ & the price of electricity $(\$ / \mathrm{kWh})$ \\
$\mathrm{U}$ & Heat exchanger overall heat transfer coefficient $\left(\mathrm{kW} / \mathrm{m}^{2}{ }^{\circ} \mathrm{C}\right)$ \\
$\mathrm{Y}$ & Yearly payment \\
\hline
\end{tabular}




\begin{tabular}{|ll|}
\hline i & The interest rate $(\%)$ \\
$\eta$ & Efficiency \\
Subscripts & \\
in & Inlet \\
out & Outlet \\
sys & System \\
h & Hot \\
c & Cold \\
w & Water \\
wf & Working fluid \\
evap & Evaporator \\
T & Turbine \\
p & Pump \\
a & Air \\
tot & Total \\
& \\
Abbreviations & \\
ORC & Organic Rankine Cycle \\
SRC & Steam Rankine Cycle \\
SIC & Specific Investment Cost \\
CRF & Capital Recovery Factor \\
FC & Fuel Cost \\
IR & Inflation Rate \\
TB & Tax Benefit \\
CT & Carbon Tax \\
LEC & Levelized Energy Cost \\
PP & Payback Period \\
NE & Net Earnings \\
\hline
\end{tabular}

\section{Introduction}

The accessibility of energy resources is an essential concern for each community. While near $80 \%$ of primary energy comes from fossil fuels [1], projects are in progress to achieve half of the electricity generation from renewable sources by 2030 [2]. Renewable energy technologies are cleaner sources of energy while they are independent of fossil fuel shortage [3], particularly when several countries such as Indonesia are estimated to deplete their fossil fuel reservoirs in five years [4,5]. Geothermal energy is known as a renewable energy source with great potential which is already underutilized around the world [6]. Geothermal energy as natural energy storage is an enormous source of energy. Recent estimation shows that around $43 \times 10^{15} \mathrm{GJ}$ energy is stored at a depth of $3 \mathrm{~km}$ from the Earth's surface [7]. The commercial application of geothermal energy resources was recorded more than 100 years ago [8], while it has been forecasted that more than $8.3 \%$ of the world's power generation would be harnessed by geothermal energy in 2050 [9]. Total geothermal power generation was reached 116,000 GWh in 2018 and can be extended to $282,000 \mathrm{GWh}$ by 2030 [2]. The geothermal energy media are dry steam, liquid water, and a mixture of steam and water in various temperatures, that go through extraction technologies [10]. Hot springs, mud pool, and geysers are also functional for hydrothermal systems in geothermal fields [11]. These media are commonly used in the direct utilization of geothermal energy for agricultural, swimming pool, and greenhouse purposes [12]. However, the indirect utilization of geothermal energy is implemented for electricity power production [13], like Chena hot springs commercial power plant that generates $210 \mathrm{~kW}$ 
of electricity power with $8.2 \%$ thermal efficiency [14]. Thermal springs with temperatures between 21 to $149^{\circ} \mathrm{C}$ exist in more than 80 countries [15]. Springs with a temperature more than the humans' body are known as hot springs [16]. In the United States of America (USA), 1072 thermal springs have been identified in 23 States [17]. Also, 3398 hot springs have been recorded in China [18]. These numbers present the promising capabilities of hot springs for implementing direct or indirect power generation. While the cost of drilling can increase to $50 \%$ of the total cost of a typical geothermal power plant project [19] due to the hardness of the rock drilling, harnessing power from hot springs as a heat source will significantly reduce the total cost of a geothermal project [10]. Natural eruption in a hot spring makes it a natural energy storage with more accessibility in comparison with the deep-well geothermal source. Using deep wells for serving the geothermal energy plant may increase the risk of geological changes, but utilizing hot springs with a natural eruption system as a heat source decreases the environmental impact in geothermal power plants[20].

The objective of this study is to provide a guideline for harnessing energy from hot springs in power generation plants. Although using low-temperature energy sources has received more attention in recent years, there is not a comprehensive investigation of power generation by hot springs. The capabilities of hot springs to generate electricity are assessed in the study by using the thermodynamic and financial approaches. A technical model of the hot springs for power plants are developed as well as an economic model for the hot springs with a wide range of temperatures and water discharge mass flow rates. The study is aimed to find the impact of hot spring temperature and water discharge mass flow rate on the energy generation capacity of a potential power plant.

\section{Background}

The natural energy storage (geothermal) resources are divided into three main categories based on their temperatures as follows [21]:

- High-temperature reservoirs (i.e., $\mathrm{T}>220^{\circ} \mathrm{C}$ ) are the most suitable ones for commercial electricity production.

- Medium-temperature reservoirs (i.e., $100<\mathrm{T}<220^{\circ} \mathrm{C}$ ) are the most available resources,

- Low-temperature geothermal resources (i.e., $\mathrm{T}<100^{\circ} \mathrm{C}$ ) have the lowest power generation among geothermal resources.

The organic Rankine cycle (ORC) is an environmentally friendly approach for generating power proposed to utilize low-grade heat sources [22]. The ORC can specifically address two main concerns of current energy systems:

1- Decreasing the energy intensity of buildings and industry by recovering waste heat [23] through the use of Combined Heat and Power (CHP) systems.

2- Developing a way to convert renewable energy sources (solar [24], geothermal [25], and biomass [26]) to electricity more efficiently [27].

The ORC is conceptually similar to a steam Rankine cycle (SRC), but the working fluid is an organic fluid instead of water [28]. The fundamental parameter in utilizing ORC refers to the organic working fluid that should be safe, environmentally friendly, and economical [29]. When water implemented as the working fluid, the following conditions must be considered [30]:

- additional pressure in the evaporator,

- excess complexity and cost of turbines,

- superheating to prevent condensing during expansion. 
While employing organic fluid instead of water has other benefits including less heat for the evaporation process, smaller temperature difference between the evaporation and condensation processes, and no superheating required within the cycle [30].

Consequently, the application of geothermal energy sources using ORC systems, especially for lowtemperature heat sources, has been increased recently [30,31]. Figure 1 shows the important historical progress in the application of ORC in geothermal energy technologies [32, 33].

\begin{tabular}{|l|l|}
\hline 10000 & -Earliest use of hot springs \\
\hline 1904 & - First electricity generation from geothermal energy \\
\hline 1913 & - First geothermal power plant built in Italy \\
\hline 1964 & - First commercial ORC application \\
\hline 1980 & - First ORC plant for a geothermal application \\
\hline & • First ORC plant for a hot spring \\
\hline
\end{tabular}

Figure 1: Historical progress records in exploiting from ORC and geothermal energy

\section{Methodology and Modeling}

\subsection{Thermodynamic Modeling}

The single-stage ORC consists of the pump, generator, evaporator, condenser, and expander, as illustrated in Figure 2. A closed-loop ORC is designed for the circulation of working fluid in the cycle, separating it from the hot source (hot spring) and cold source (cold water or air). The operation of the cycle contains four steps [36,37]:

1- The high-pressure liquid turns to vapor working fluid in the evaporator by receiving heat from a hot source and exits the evaporator.

2- The high-pressure vapor expands via the expander joint with the electrical power generator, and therefore, generates the electricity.

3- The low-pressure vapor working fluid exits from the expander enters the condenser to get cooled down. The low-pressure vapor turns to saturated liquid by rejecting heat to the ambient cold air in an air-medium heat exchanger. 
4- The low-pressure saturated working fluid enters the pump to increase its pressure. The pump makes the working liquid pressure equals to the evaporator pressure level. Then, the high-pressure working fluid is ready to enter the evaporator to repeat the cycle.

Applying the mass continuity equation (equation (1)) to the energy plant is needed to find the mass flow rates of inlet and outlet streams for each component [35,36].

$$
\sum \dot{m}_{\text {in }}-\sum \dot{m}_{\text {out }}=\frac{d m_{\text {sys }}}{d t}
$$

where $\dot{m}_{\text {in }}$ and $\dot{m}_{\text {out }}$ are mass flow rates $(\mathrm{kg} / \mathrm{s})$ at the inlet and outlet of a system, respectively, and $\frac{d m_{\text {sys }}}{d t}$ is mass storage rate within a system

Applying energy rate balance to the energy plant allows a deeper understanding of the energy level of the ORC components in the form of work and heat. The energy balance can be written as:

$$
\left[\sum(\dot{Q}-\dot{W})_{i n}-\sum(\dot{Q}-\dot{W})_{o u t}\right]+\sum \dot{m}_{i n}\left(h+\frac{V^{2}}{2}+g z\right)_{\text {in }}-\sum \dot{m}_{\text {out }}\left(h+\frac{V^{2}}{2}+g z\right)_{o u t}=\frac{d E_{\text {sys }}}{d t}
$$

Here, $h$ is the specific enthalpy in $\mathrm{kJ} / \mathrm{kg}, \dot{Q}$ and $\dot{W}$ are heat and work transfer crossing the component boundaries in $\mathrm{kJ} / \mathrm{s}$, respectively. Also, $\mathrm{V}$ is stream velocity in $\mathrm{m} / \mathrm{s}$, and $\mathrm{z}$ is stream elevation in $\mathrm{m} . \frac{d E_{s y s}}{d t}$ is the energy storage rate within a system in $\mathrm{kJ} / \mathrm{s}$.

To find the heat transfer area of the evaporator and condenser, the Logarithmic Mean Temperature Difference (LMTD) is used [40]. The LMTD is a well-known method to evaluate the performance of the heat exchangers and is suitable for the evaporation and condensation process in the heat exchangers [41]. The LMTD values associated with the evaporator and condenser can be written as follows.

$$
\Delta T_{l m}=\left(\left(T_{h, \text { out }}-T_{c, \text { in }}\right)-\left(T_{h, \text { in }}-T_{c, \text { out }}\right)\right) / \ln \left(\frac{\left(T_{h, \text { out }}-T_{c, \text { in }}\right)}{\left(T_{h, \text { in }}-T_{c, \text { out }}\right)}\right)
$$

where $\Delta T_{l m}$ is the logarithmic mean temperature difference in ${ }^{\circ} \mathrm{C} . T_{h, o u t}$ and $T_{h, \text { in }}$ are hot stream temperature in the outlet and inlet of the heat exchanger (i.e., evaporator or condenser) in ${ }^{\circ} \mathrm{C}$, respectively. Also, $T_{c, o u t}$ and $T_{c, i n}$ are cold stream temperature in the outlet and inlet of the heat exchanger (i.e., evaporator or condenser) in ${ }^{\circ} \mathrm{C}$, respectively. 


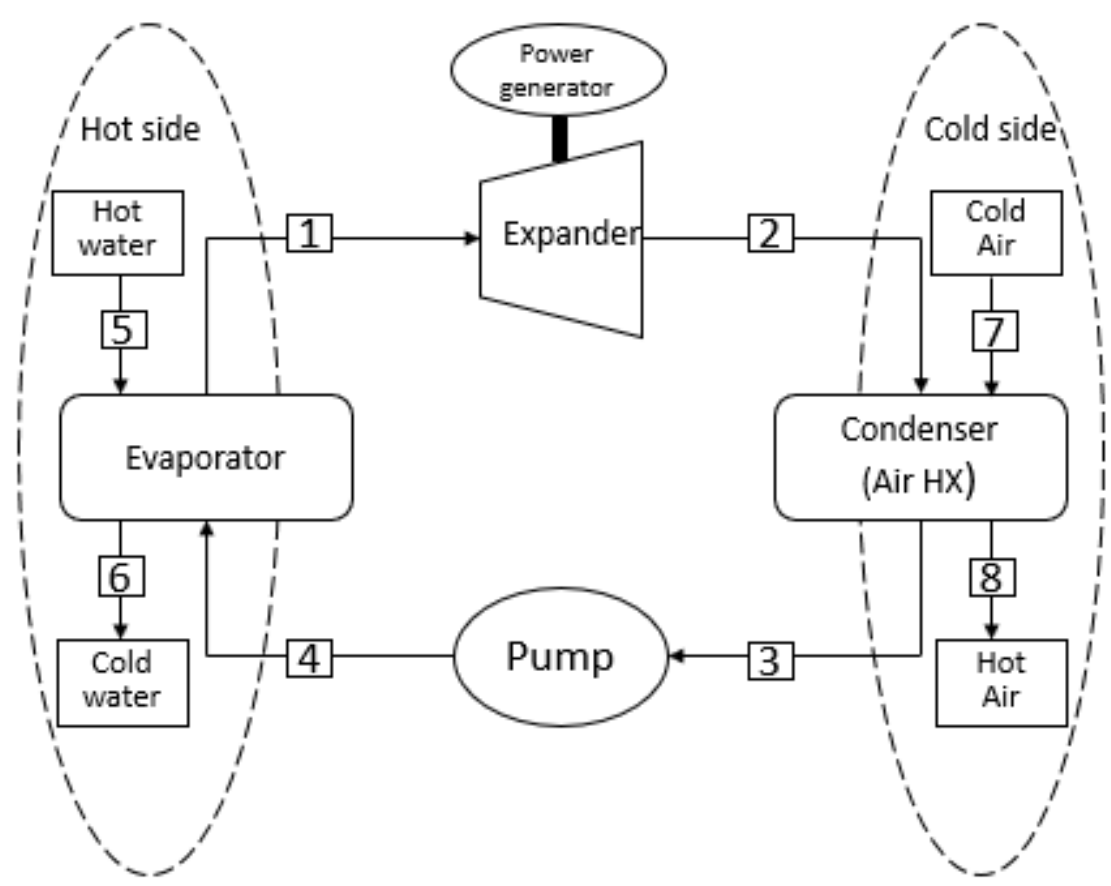

Figure 2: Schematic of ORC power generation by using hot springs

Equations (1) and (2) are applied on each component of the ORC cycle presented in Figure 2. The following assumptions are used to develop the thermodynamic model of the system equations (4) to (7).

- ORC system is at steady-state condition,

- A constant amount of working pressure in condenser and evaporator,

- Inlet and outlet sections of each component are at thermodynamic equilibrium,

- Pump and the expander (i.e., turbine) are adiabatic,

- The changes in potential energy and kinetic energy are negligible.

Applying equation (2) on the ORC cycle leads to equation (8). The customized results are equations (4), (5), (6), and (7) which is used for calculation of component energy and heat transfer within hot spring energy plant.

$$
\begin{array}{ll}
\text { Evaporator: } & Q_{i n}=\dot{m}_{w} \times\left(h_{5}-h_{6}\right)=\dot{m}_{w f} \times\left(h_{1}-h_{4}\right)=U_{\text {evap }} \times A_{\text {evap }} \times \Delta T_{l m 41} \\
\text { Expander: } & W_{T}=\eta_{m} \times \dot{m}_{w f}\left(h_{1}-h_{2, s}\right)=\eta_{m} \times \eta_{p} \times\left(h_{1}-h_{2}\right) \\
\text { Condenser: } & Q_{\text {out }}=\dot{m}_{a} \times\left(h_{8}-h_{7}\right)=\dot{m}_{w f} \times\left(h_{2}-h_{3}\right)=U_{\text {cond }} \times A_{\text {cond }} \times \Delta T_{l m 23} \\
\text { Pump: } & W_{p}=\dot{m}_{w f}\left(h_{4, s}-h_{3}\right)
\end{array}
$$

Where the $U_{\text {evap }}$ and $U_{\text {cond }}$ are the overall heat transfer coefficient of the evaporator and condenser in $\mathrm{kW} / \mathrm{m}^{2} .{ }^{\circ} \mathrm{C}$, respectively. Also, $A_{\text {evap }}$ and $A_{\text {cond }}$ are the heat transfer areas of the evaporator and condenser in $\mathrm{m}^{2}$, respectively. $\eta_{m}, \eta_{T}$, and $\eta_{p}$ represent the generator efficiency, isentropic efficiency of the expander, and isentropic efficiency of the pump, respectively. In addition, $\dot{m}_{w f}, \dot{m}_{w}$, and $\dot{m}_{a}$ denote the mass flow rate of working fluid, water, and air in $\mathrm{kg} / \mathrm{s}$, respectively. $W_{T}$ and $W_{p}$, show produced work in the expander and required work in the pump in $\mathrm{kW}$, respectively. 
The work output and thermal efficiency of the ORC are determined by equations (8) and (9) as follows.

$$
\begin{aligned}
W_{\text {net }} & =W_{T}-W_{p} \\
\eta & =\frac{W_{\text {net }}}{Q_{\text {in }}}
\end{aligned}
$$

Here, $W_{\text {net }}$ is power output of the cycle in $\mathrm{kW}$, and $\eta$ is the thermal efficiency of the cycle. Also, $Q_{\text {in }}$ represents the heat transfer rate to organic fluid in the evaporator in $\mathrm{kW}$.

\subsection{Enviro-Economic Modeling}

Cost estimation is an essential part of a feasibility study. The economic model addresses both economics of the energy plant as well as its environmental impact. The overall cost of the plant is categorized into three major costs: initial investment, operating cost, and environmental business cost [37].

\subsubsection{Initial investment:}

The initial investment estimation in the ORC system was estimated by finding the cost of each component. Two heat exchangers in the roles of the evaporator and condenser were implemented in the design. Therefore, two heat exchangers, a pump, an expander, and an electricity generator were the main component of the ORC system. The cost of labor, working fluid, and pipes were not considered since they can vary from one project to another. Ultimately, the investment cost can be estimated by equation (10).

$$
C_{\text {tot }}=C_{\text {evaporator }}+C_{\text {condenser }}+C_{\text {turbine }}+C_{\text {pump }}+C_{\text {generator }}
$$

The Specific Investment Cost (SIC) is the ration of the investment cost to generated power as shown in the below equation [38]:

$$
S I C=\frac{C_{t o t}}{W_{n e t}}
$$

The capital recovery factor (CRF) is estimated based on the equations (12). The cost of a loan on the energy plant is calculated through the CRF, which results in a yearly stream of payments for the loan in equation (13) $[39,40]$ :

$$
\begin{aligned}
& C R F=\frac{i(1+i)^{q}}{(1+i)^{q}-1} \\
& Y=\left(C R F \times C_{t o t}\right)
\end{aligned}
$$

Here, $\mathrm{i}$ represents the interest rate, and q is the number of yearly payments. Also, Y denotes yearly payment

Considering the variation of value of money over time, the initial investment is written as:

$$
\text { Initial investment }=\sum_{a=1}^{q} Y(1+I R)^{a}
$$

where $a$ represents the number of amortization years ranging from 1 to q, and IR is the inflation rate. 


\subsubsection{Operating cost:}

The operating cost accounts for fuel, insurance, and maintenance costs which vary during the life of the energy plant because of the changing value of the money, are presented in equation (15).

$$
\text { Operating cost }=\sum_{g=1}^{n}(F C+I \& M)(1+I R)^{g}
$$

Here, FC is the annual fuel cost which equals 0 for a renewable energy power generation system. Also, $\mathrm{I} \& \mathrm{M}$ is the insurance and maintenance of annual costs, and $\mathrm{g}$ is the performance years of the energy plant ranging from 1 to $\mathrm{n}$.

\subsubsection{Environment Business Cost:}

The environmental effects of using the energy plant can be quantified in the forms of carbon taxes and tax benefits as presented in the below equation [37]:

$$
\text { Environment Business Cost }=\sum_{g=1}^{n} C T(1+I R)^{g}-\sum_{g=1}^{n} T B(1+I R)^{g}
$$

By combining the cost of the initial investment (equation (14)), operation cost (equation (15)), and environmental cost (equation (16)), the overall cost of the energy plant can be determined by equation (17):

$$
\text { Overall cost }=\text { Initial investment }+ \text { Operating cost }+ \text { Environmental business cost }
$$

Levelized Energy Cost (LEC) is a useful tool for comparing different energy generation systems that are calculated using equation (18). The LEC is the ratio of the system cost to total net power output by ignoring the field capital cost and field O\&M cost that can be estimated with the below equation [40]:

$$
L E C=\frac{\text { Overall cost }}{W_{\text {net }} \times t_{o p} \times n}
$$

where $t_{o p}$ is the operation hours in a year, and $\mathrm{n}$ is the energy plant lifetime in years.

Based on the initial investment and the annual net earnings (NE), the static Payback Period (PP) of the energy plant can be estimated by the following equation [41]:

$$
P P=\frac{\text { Initial Invetment }}{P_{e} \times W_{\text {net }} \times t_{o p}}
$$

Here $P_{e}$ represents the price of electricity in $\$ / \mathrm{kWh}$.

\subsection{Energy Plant Simulation Software}

Mass and energy models in the designed ORC need to be simulated in software that takes advantage of both library of organic fluid thermodynamic properties and the energy plant components. The Aspen Plus (V9) is a software that provides such a capability suitable for implementing in this study by having a library of thermodynamic properties of the organic fluid as well as an ability of modeling components in an energy plant. Aspen Plus is capable of modeling the heat exchangers with the phase-change process in the evaporator and condenser in the ORC plant. Aspen Plus is the leading chemical engineering process simulator in the market that allows the user to build the process model and simulate using complex calculations. 


\section{Sizing the ORC System}

The model of a single-stage ORC plant for converting the energy of the hot springs to electricity is developed by Aspen Plus V9 as it is demonstrated in Figure 3. To estimate the capability of a power generation with an ORC system from a hot spring the components need to be sized. To do so, several considerations are assumed as illustrated in sections 4.1-4.7.

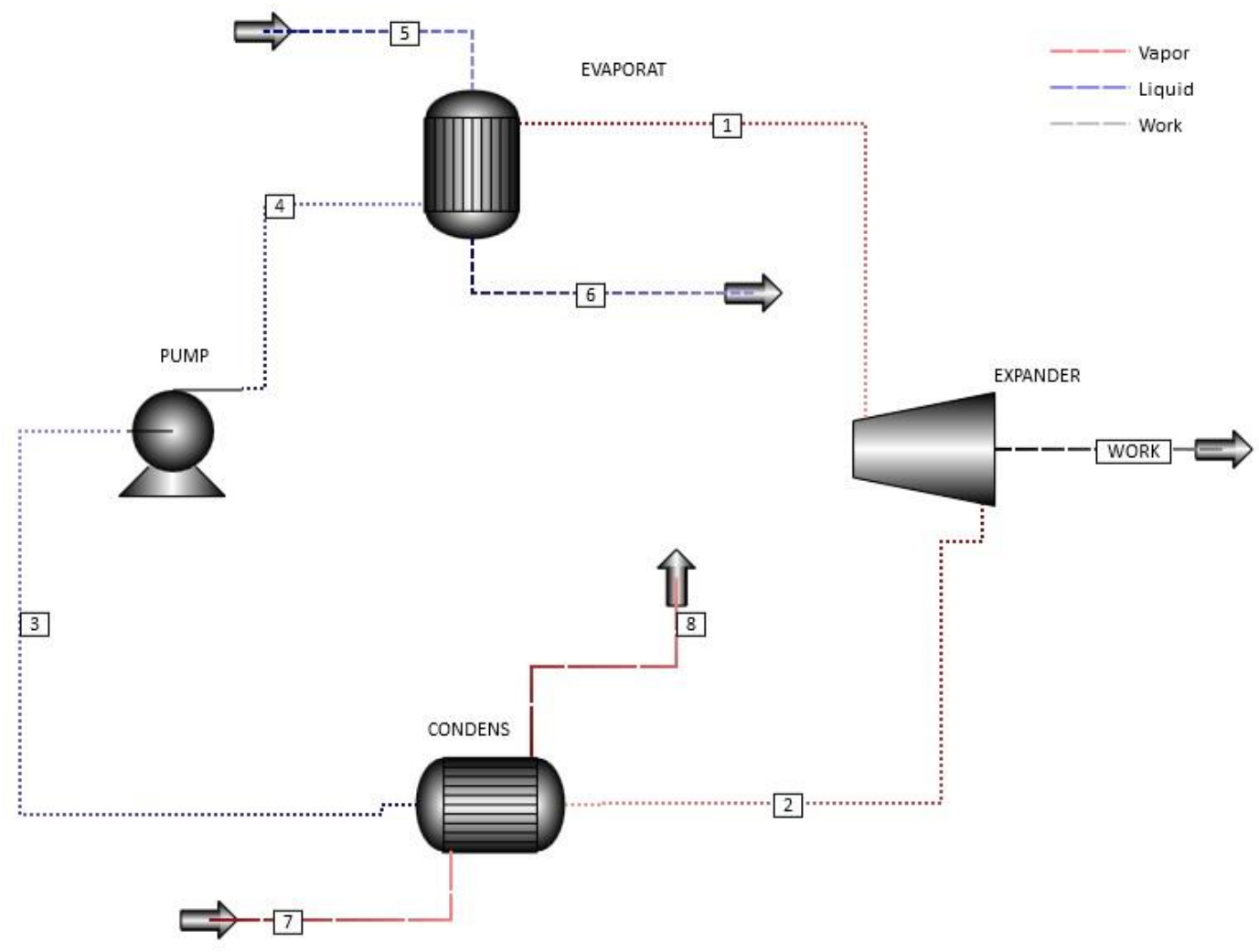

Figure 3: Aspen plus software model for ORC power generation

\subsection{Organic working fluid selection}

R227ea as a non-flammable and non-toxic organic fluid refrigerant is suitable for low pressure, lowtemperature applications with high efficiency [42-46], especially when the hot source temperature is lower than $92{ }^{\circ} \mathrm{C}[47,48]$. Since changes of the entropy with the temperature in R227ea is positive, it is known as dry organic fluid; hence, this organic fluid does not need the superheat before its expansion process in ORC [48] while R227ea is selected for the low-temperature ORC system. Table 1 exhibits the properties of R227ea. 
Table 1: Physical properties of R227ea

\begin{tabular}{|l|l|}
\hline Properties & Data \\
\hline Chemical name & $1,1,1,2,3,3,3$-Heptafluoropropane \\
\hline Chemical formula & $\mathrm{CF} 3 \mathrm{CHFCF} 3$ \\
\hline Molecular weight & $170.03 \mathrm{~g} / \mathrm{mol}$ \\
\hline Boiling temperature & $-15.6^{\circ} \mathrm{C}$ \\
\hline Critical temperature & $102.8^{\circ} \mathrm{C}$ \\
\hline Critical pressure & $29.8 \mathrm{bar}$ \\
\hline
\end{tabular}

\subsection{Organic fluid working pressure}

There are high and low pressures in an ORC system that are determined by the organic fluid pressure in the evaporator and condenser in the ORC system. Since the condenser is an air-cooled heat exchanger, the low pressure of the cycle cannot be lower than 5 bar due to ambient temperature which is $18{ }^{\circ} \mathrm{C}$. Therefore, the condenser pressure is considered as 5 bar. The evaporation is depending on the evaporator pressure. The evaporation pressure categories are shown in Table 2 based on the hot springs temperature range $[44,45,49]$.

Table 2: Evaporator pressure based on hot spring temperature

\begin{tabular}{|l|l|}
\hline Evaporator pressure (bar) & Hot source temperature $\left({ }^{\circ} \mathrm{C}\right)$ \\
\hline 9 & $60-70$ \\
\hline 12 & $71-80$ \\
\hline 15 & $81-90$ \\
\hline
\end{tabular}

\subsection{Component specification}

The component using in the ORC have different specifications. The pump needs the energy to maintain the required pressure of working fluid through the cycle. The expander provides mechanical energy for the power generator by expanding the working fluid. The isentropic efficiency of the pump and expander are assumed to be $75 \%$. Power generator which is coupled with the expander to convert mechanical energy to electrical energy efficiency is $95 \%$. Also, overall heat transfer in heat exchanger is required for calculation in both evaporator and condenser have assumed to be $0.85 \mathrm{~kW} / \mathrm{m}^{2}{ }^{\circ} \mathrm{C}$.

\subsection{Cold source temperature}

Although water is a better medium for the condenser in geo-technology, over the possibility of water shortage in the region, the air has been considered as a circulating medium for the condenser. Using the airmedium heat exchanger as a condenser in the ORC plant not only reduces the water consumption of the plant by using the cool air on the higher elevations of hot springs, but it leads to financial advantages over the initial cost, operation cost, and I\&M cost. It is reported that large-scale geothermal power plants consume $20 \mathrm{~L} / \mathrm{MWh}$ water on average [50], while the air cooling condenser ORC plant is free of freshwater intake. Since hot springs are located in mountainous areas with colder temperatures (where the volcanic activity of the earth is probable), using the air as a medium in the condenser is practical. The cold source temperature has been considered to the ambient temperature of $18^{\circ} \mathrm{C}$. 


\subsection{Hot source temperature}

The evaporators can evaporate the organic fluid when the hot source temperature is more than $59{ }^{\circ} \mathrm{C}$. Usually, the hot springs with a temperature between $60-90{ }^{\circ} \mathrm{C}$ are widely spread, and based on this range the present study has been conducted. There are few springs with a temperature of more than $90{ }^{\circ} \mathrm{C}$ throughout the world.

\subsection{Hot source mass flow rate}

The water discharge mass flow rate from the hot springs has been assumed as the mass flow rate of the hot fluid. The mass flow rate range of hot springs has considered between $5 \mathrm{~kg} / \mathrm{s}$ to $50 \mathrm{~kg} / \mathrm{s}$ to cover the hottest springs.

\subsection{Economic assumption}

The life span of the ORC system has assumed 20 years [51], and the annual I\&M cost has assumed 3\% of the principal cost. The amortization of 10 years with an interest rate of 5\%, and an inflation rate of $2 \%$ [37]. The production hours in a year for the ORC has considered 8000 hours per year [52]. The USA average electricity cost in 2020 [53] of $0.1045 \$ / \mathrm{kWh}$ has been defined as electricity cost in this study.

All the technical and economic input data and assumptions in sizing the ORC plant are summarized in Table 3.

Table 3: Assumptions in sizing the energy plant

\begin{tabular}{|c|c|c|}
\hline \multirow{10}{*}{$\begin{array}{l}\text { Technical } \\
\text { study } \\
\text { assumptions }\end{array}$} & Working fluid & R227ea \\
\hline & Working fluid pressure in the condenser & 5 bar \\
\hline & Working fluid pressure in the evaporator & $\begin{array}{l}15 \text { bar }(\text { hot source } \\
\left.\text { temperature } \geq 81^{\circ} \mathrm{C}\right) \\
12 \text { bar }(71 \leq \text { hot source } \\
\left.\text { temperature }<81^{\circ} \mathrm{C}\right) \\
9 \text { bar }(60 \leq \text { hot source } \\
\left.\text { temperature }<71^{\circ} \mathrm{C}\right)\end{array}$ \\
\hline & Pump isentropic efficiency & $75 \%$ \\
\hline & Expander (turbine) isentropic efficiency & $75 \%$ \\
\hline & Electricity generator efficiency & $95 \%$ \\
\hline & Heat exchanger overall heat transfer coefficient & $0.85 \mathrm{~kW} / \mathrm{m}^{2}{ }^{\circ} \mathrm{C}$ \\
\hline & Air temperature (cooling source) & $18^{\circ} \mathrm{C}$ \\
\hline & Hot springs temperature & $60-90{ }^{\circ} \mathrm{C}$ \\
\hline & Hot springs discharge mass flow rate & $5-50 \mathrm{~kg} / \mathrm{s}$ \\
\hline \multirow{7}{*}{$\begin{array}{l}\text { Economical } \\
\text { study } \\
\text { assumptions }\end{array}$} & A lifetime of energy plant & 20 years \\
\hline & Amortization period & 10 years \\
\hline & $\mathrm{I} \& \mathrm{M}$ cost & $3 \%$ of investment cost \\
\hline & Interest rate & $5 \%$ \\
\hline & Inflation rate & $2 \%$ \\
\hline & Working hours per year & 8000 hours \\
\hline & Electricity cost & $0.1045 \$ / \mathrm{kWh}$ \\
\hline
\end{tabular}

To clarify the provided information in Figure 3 and the technical study assumptions in Table 3 the parameters used at operating points within the energy plant are shown in Table 4 . Point 1 to 8 are the defined point in Figure 3. The parameters that need to be calculated with the equations and assumptions are illustrated. 
Table 4: Operating points parameters which is shown in Figure 3

\begin{tabular}{|c|c|c|c|c|c|c|c|c|}
\hline point & 1 & 2 & 3 & 4 & 5 & 6 & 7 & 8 \\
\hline Fluid & R227ea & R227ea & R227ea & R227ea & $\begin{array}{c}\text { Hot } \\
\text { spring } \\
\text { water }\end{array}$ & $\begin{array}{c}\text { Hot } \\
\text { spring } \\
\text { water }\end{array}$ & Air & Air \\
\hline $\begin{array}{c}\text { Mass flow } \\
\text { rate }(\mathrm{kg} / \mathrm{s})\end{array}$ & & & & & 5 to 50 & $\begin{array}{c}5 \text { to } \\
50\end{array}$ & & \\
\hline $\begin{array}{c}\text { Temperature } \\
\left({ }^{\circ} \mathrm{C}\right)\end{array}$ & 9 & 5 & 5 & 9 & 1 & 1 & 1 & 1 \\
\hline $\begin{array}{c}\text { Pressure } \\
(\text { bar })\end{array}$ & 12 & 5 & 5 & 12 & 60 to & & 18 & \\
\hline Phase & $\begin{array}{c}\text { Saturate } \\
\text { d vapor }\end{array}$ & $\begin{array}{c}\text { Saturate } \\
\text { d vapor }\end{array}$ & $\begin{array}{c}\text { Saturate } \\
\text { d liquid }\end{array}$ & $\begin{array}{c}\text { Saturate } \\
\text { d liquid }\end{array}$ & Liquid & Liquid & gas & gas \\
\hline
\end{tabular}

\section{Analysis}

\subsection{Technical analysis}

By thermodynamic modeling and simulation of the ORC plant, the total electricity generation capacity, thermal efficiency, required pump power, and total heat transfer area in evaporator and condenser can be determined for a wide range of hot springs. Tables 3 and 4 show the data used for the analysis. Figure 4 shows the flow chart of the technical analysis based on the available data and developed equations and the outcomes in different steps of the analysis.

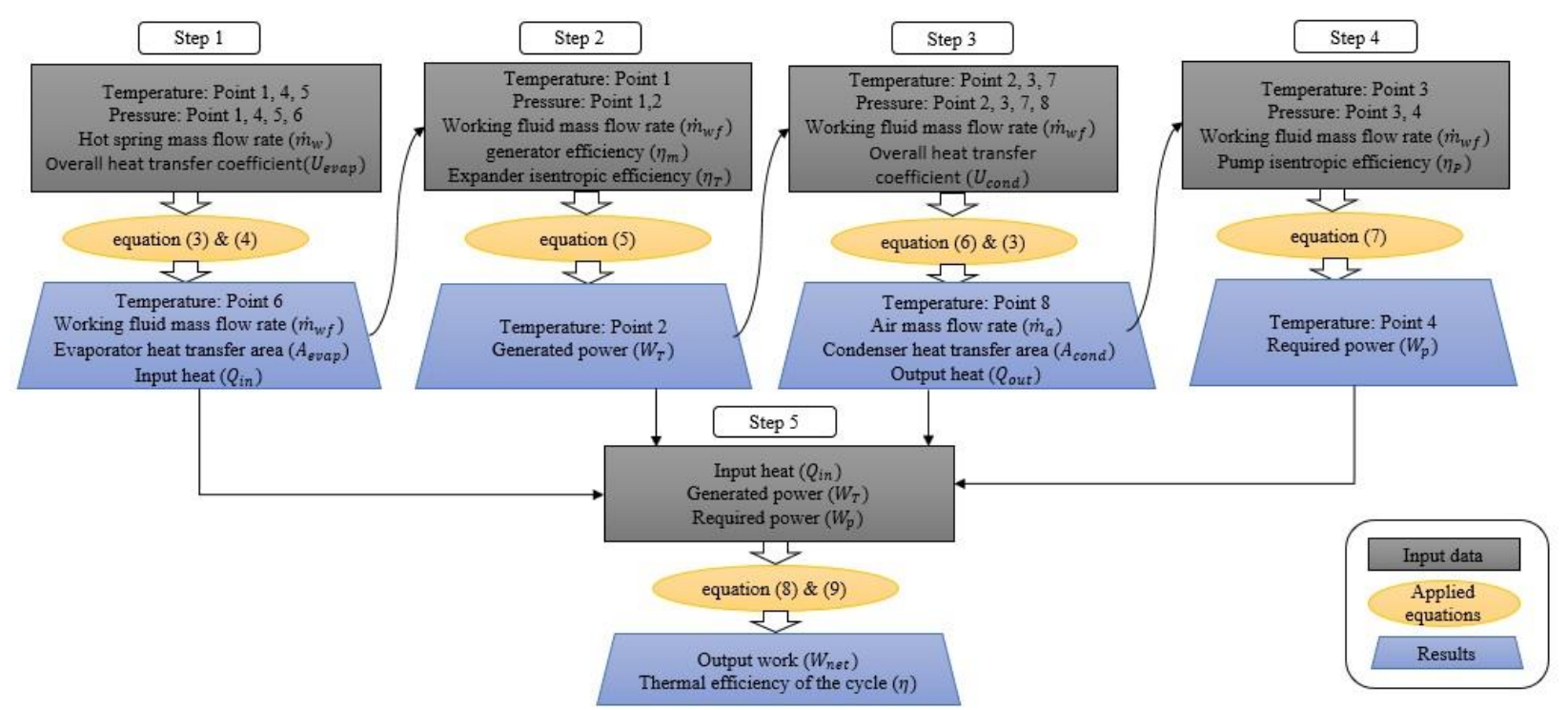

Figure 4: Flowchart of the Technical Analysis of ORC energy plant 


\subsection{Economic analysis}

\subsubsection{Initial investment}

The economic analysis of the energy plant is determined by considering major costs and revenues during its lifetime. Based on the results of the technical analysis of the energy plant, the specification of every component in the designed energy plant is provided. The cost of every component is estimated by using the average of three actual quotes from American suppliers. The heat transfer area, fluids mass flow rates and total transferred heat in the heat exchangers were provided as required information for the industry to design an applicable heat exchanger with a proportionate cost. Expander and electric generator prices depend on the estimated power generation in technical analysis. Heat exchangers, expanders, and pumps price quotes are sized by suppliers according to the technical results. The initial investment is determined using the suppliers' quote by equation (10). By implementing the value of the power generation and initial cost in equation (11), the SIC value is been determined. Implementing interest rate and amortization information from Table 3 to equations (12) and (13) leads to finding CRF value. The influences of the inflation rate on the initial investment are illustrated using equation (14) and the inflation rate value in Table 3.

\subsubsection{Operating cost}

Operating cost which is $3 \%$ of the initial cost is calculated by applying I\&M value on equation (15). The influence of the inflation rate on the yearly annual cost can be determined by applying the inflation rate from Table on equation (15).

\subsubsection{Environment business cost:}

Although $\mathrm{CO}_{2}$ emission (as an indicator of the environmental impact) is a vital term in analyzing the environmental business cost in energy systems [54], carbon tax and tax benefit affect ORC geothermal energy plants' overall cost based on the region environmental policies and regulations. Therefore, equation (16) has not been used in this study since the focus of this study is not on a specific location.

By having the initial investment, operating cost, and environmental business cost, using equation (17), the overall cost of the energy plant consisting of these three major costs is estimated. Implementing yearly working hours and lifespan of the energy plant from Table 3 into equation (18) results in the energy plant levelized energy cost. Finally, to find the payback period of the hot spring energy plant, equation (19) is used with considering the electricity price from Table 3. PP depends on the initial investment, power generation, working hours of the hot spring energy plant in a year, and the electricity price in the consuming location.

Figure 5 shows the economic analysis of the ORC energy plant in sequence in a flowchart format. 


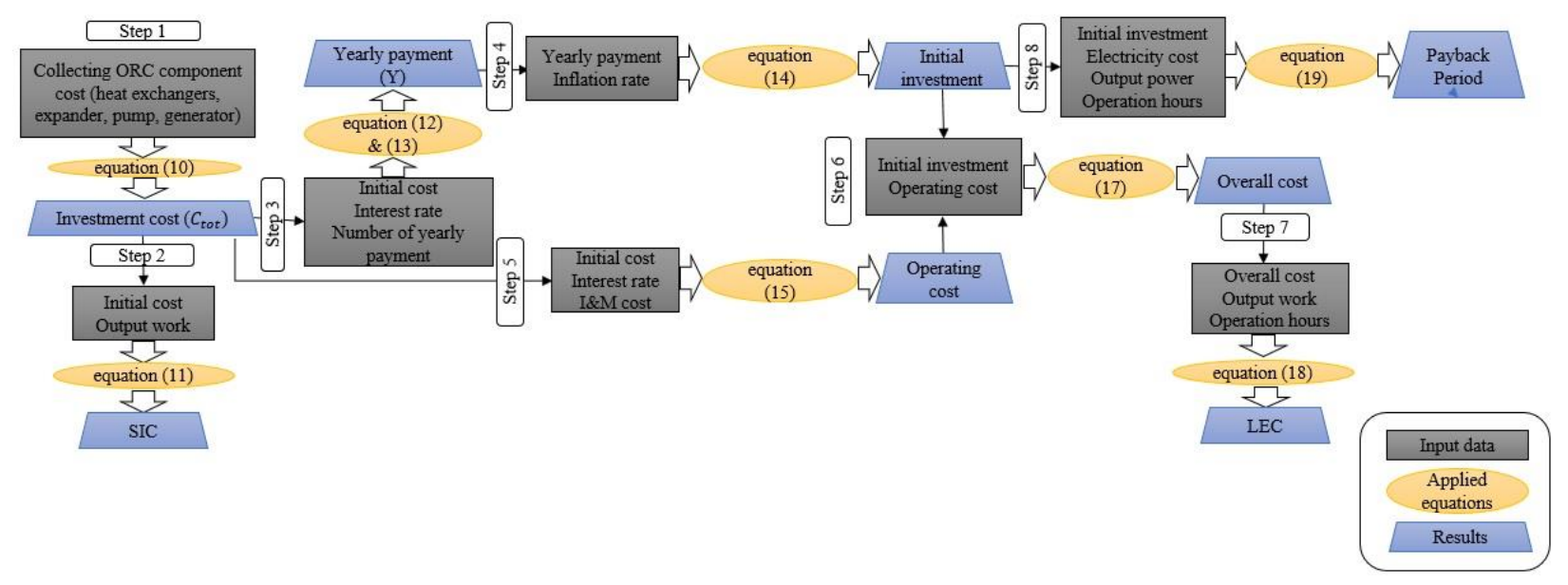

Figure 5: Flowchart of the Economic Analysis of ORC energy plant

\section{Results and Discussion}

\subsection{Technical Outcomes}

The purpose of the study was to design a power generation system for hot springs and present a technoeconomic analysis for the designed system. On the technical side, one set of technical modeling results for a hot spring with the $76^{\circ} \mathrm{C}$ temperature and $25 \mathrm{~kg} / \mathrm{s}$ water discharge mass flow rate is presented in Table 5 . This table determines components specifications in the designed ORC plant.

Table 5: Components specifications in the designed ORC plant for a selected hot spring

\begin{tabular}{|l|l|l|l|}
\hline $\begin{array}{l}\text { Maximum evaporated working fluid } \\
\text { mass flow rate }(\mathrm{kg} / \mathrm{s})\end{array}$ & 13.4 & Total generated work in ORC $(\mathrm{kW})$ & 96.8 \\
\hline $\begin{array}{l}\text { Total heat transferred in the evaporator } \\
(\mathrm{kW})\end{array}$ & 1620.0 & $\begin{array}{l}\text { Total heat transfer area in heat } \\
\text { exchangers }\left(\mathrm{m}^{2}\right)\end{array}$ & 112.2 \\
\hline Generated power in expander $(\mathrm{kW})$ & 105.9 & The thermal efficiency of the cycle & 5.9 \\
\hline Required work in the pump $(\mathrm{kW})$ & 9.1 & \multicolumn{2}{|l}{} \\
\hline
\end{tabular}

The net generated power by hot springs is presented in Figure 6. The results are based on the hot spring mass flow rate at different temperatures of hot water in the hot spring and pressure of the evaporator in a single-stage ORC.As can be seen, by increasing the mass flow rate of the hot spring, the power generation grows, while it can be intensified by the growth of water temperature in the hot spring. It can be concluded that by increasing the temperature and discharge mass flow rate of hot springs the generated power intensely improves. A hot spring with a water discharge mass flow rate of $50 \mathrm{~kg} / \mathrm{s} \mathrm{a} 90{ }^{\circ} \mathrm{C}$ has an approximate net power output of $303 \mathrm{~kW}$, while a hot spring with a water discharge mass flow rate of $5 \mathrm{~kg} / \mathrm{s}$ at $90{ }^{\circ} \mathrm{C}$ is capable of net power generation of about $30 \mathrm{~kW}$. If the temperature of the latter hot spring drops to $60{ }^{\circ} \mathrm{C}$, the net power generation falls lower than $10 \mathrm{~kW}$. 


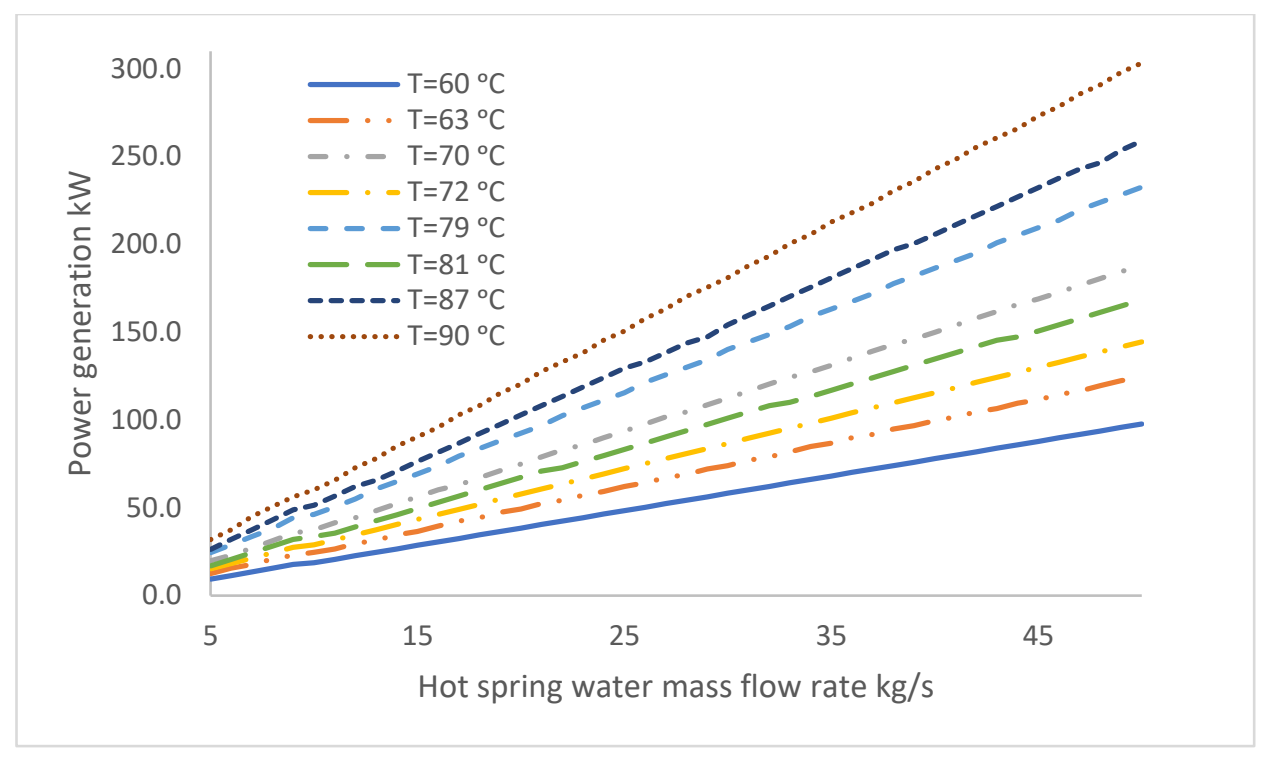

Figure 6: The total working output of ORC using hot spring

The technical results determine three different values for the thermal efficiency of the energy plant, calculated for three different defined working fluid pressure levels. When an evaporator pressure of 15 bar, 12 bar, and 9 bar, the ORC's thermal efficiency is about $7.2 \%, 5.9 \%$, and $4.2 \%$, respectively. Since the evaporator and condenser pressure are determined by hot spring temperature and working fluid thermophysical properties, it can be concluded that the energy plant thermal efficiency has related to the temperature of hot spring and working fluid selection. Figure 7 indicates the thermal efficiency of the energy plant on a T-S diagram for the working fluid (R227ea) in three different evaporator pressure range.

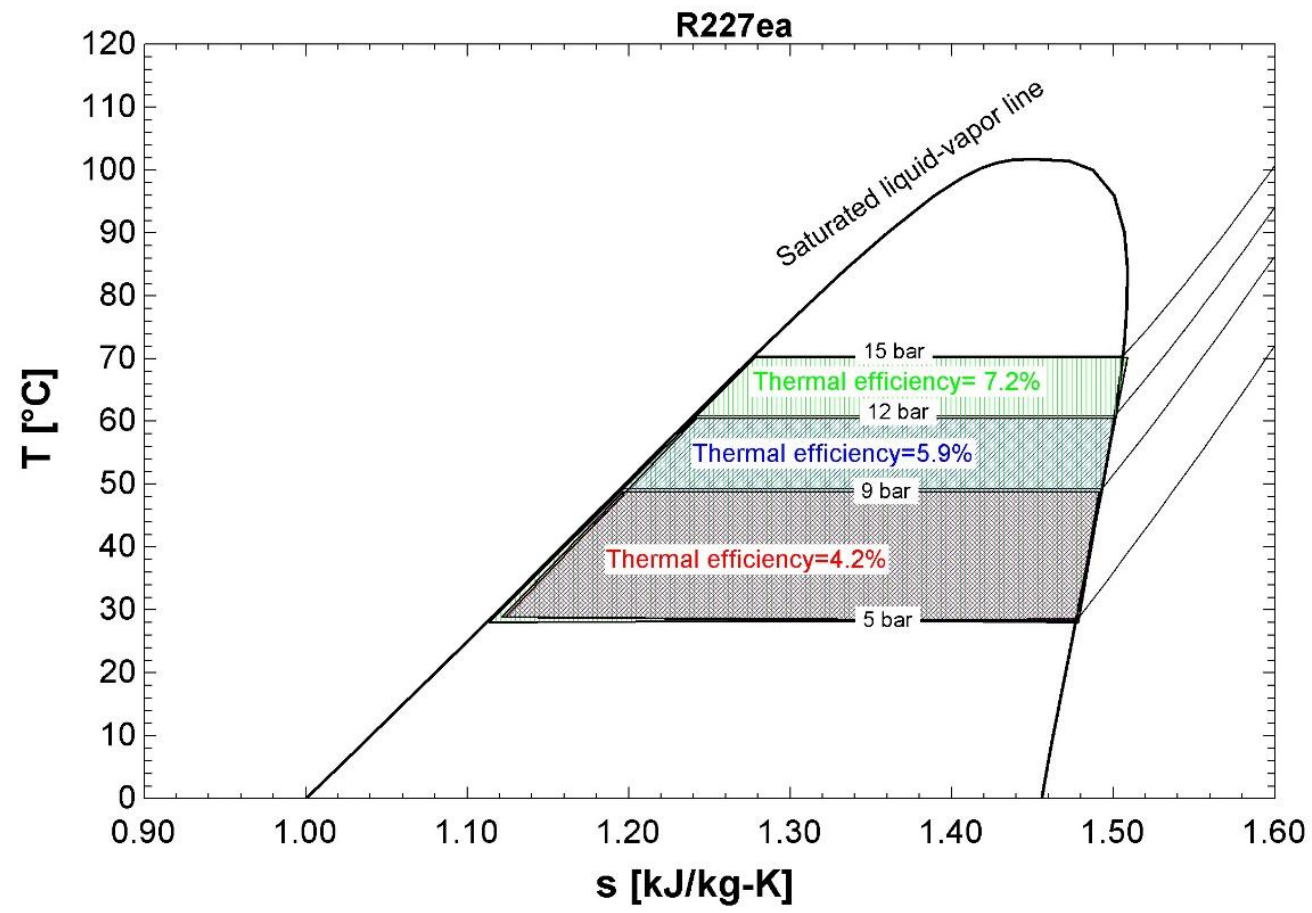

Figure 7: Thermal efficiency of the ORC in the T-S diagram for three working pressures 
The heat transfer area is a crucial parameter in the performance of heat exchangers that impact the fabrication heat exchanger and its cost. In the ORC plant, two heat exchangers have been used, refer to Figure 3. Calculating the heat transfer area in the heat exchangers is a result of the study which varies in the energy plant with different working fluid and hot spring water mass flow rates and temperatures. A hot spring with a water discharge mass flow rate of $5 \mathrm{~kg} / \mathrm{s}$ at $60{ }^{\circ} \mathrm{C}$ needs a heat exchanger with a $20 \mathrm{~m}^{2}$ heat transfer area which at maximum rate can evaporate the working fluid with $1.8 \mathrm{~kg} / \mathrm{s}$ mass flow. Similarly, a hot spring with a $50 \mathrm{~kg} / \mathrm{s}$ water discharge mass flow rate at $90{ }^{\circ} \mathrm{C}$ requires $230 \mathrm{~m}^{2}$ area in its heat exchanger to evaporate working fluid with $34.2 \mathrm{~kg} / \mathrm{s}$ mass flow rate as maximum. The results illustrate that how the total heat transfer area in heat exchangers depends on the hot spring discharge mass flow rate and its temperature. Since heat-exchanger cost accounts for up to 50\% of the total ORC project costs [55], hot springs with higher discharge water mass flow rate and higher temperature are more costly.

\subsection{Economic results}

The results of the economic analysis illustrate the feasibility of performing a hot spring energy plant project in different circumstances. To find the initial investment cost, the actual price of the ORC components is collected from the US suppliers as shown in Table 6. By using the provided information in Table 7, the cost curve of each component is plotted which is presented in Figure 8. The provided component cost curves determine the component with different properties.

Table 6: Collected price for ORC components

\begin{tabular}{|c|l|l|l|}
\hline & Unit & & Price $\$$ \\
\hline ORC heat & Total heat & $\mathrm{A}=35 \mathrm{~m}^{2}$ & 37,000 \\
\cline { 3 - 4 } exchanger & transfer area & $\mathrm{A}=100 \mathrm{~m}^{2}$ & 68,000 \\
\cline { 3 - 4 } & & $\mathrm{A}=188 \mathrm{~m}^{2}$ & 101,000 \\
\hline ORC expander & Generated & $10 \mathrm{~kW}$ & 25,000 \\
\cline { 3 - 4 } $\begin{array}{c}\text { and electric } \\
\text { generator }\end{array}$ & power & $75 \mathrm{~kW}$ & 150,000 \\
\cline { 3 - 4 } & & $300 \mathrm{~kW}$ & 300,000 \\
\hline ORC pump & \multirow{2}{*}{$\begin{array}{c}\text { Required } \\
\text { Power }\end{array}$} & $5 \mathrm{~kW}$ & 1,000 \\
\cline { 3 - 4 } & & $10 \mathrm{~kW}$ & 11,000 \\
\cline { 3 - 4 } & & $15 \mathrm{~kW}$ & 22,000 \\
\hline
\end{tabular}




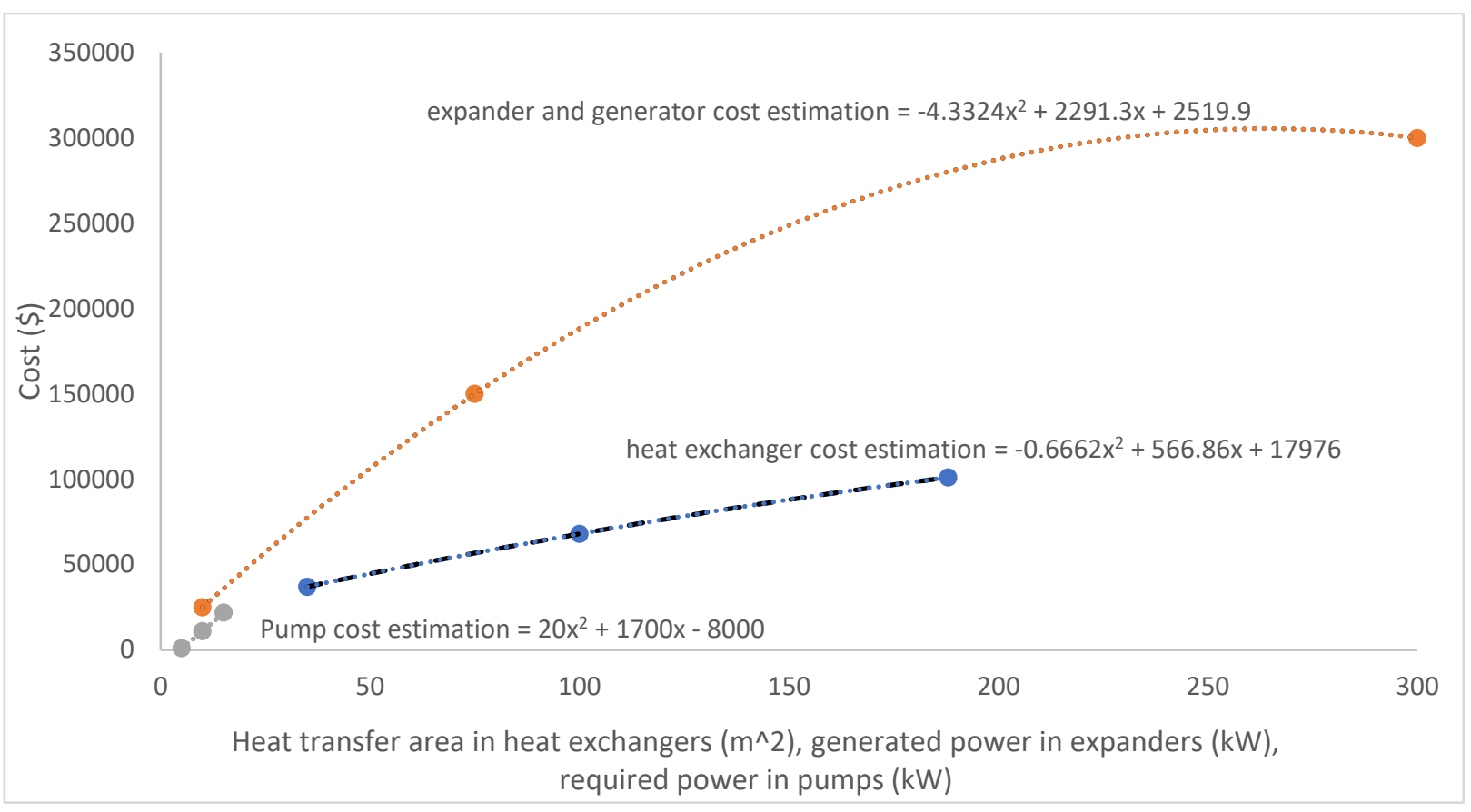

Figure 8: Cost estimation curve for ORC components

Figure 9 presents the SIC of generated electricity through energy plant for different hot spring temperature and water discharge mass flow rate. It can be seen by increasing the temperature and water discharge mass flow rate of hot springs, the cost of the energy plant per amount of generated power shrinks. The SIC for the ORC plant with $60 \mathrm{C}$ hot water temperature and $5 \mathrm{~kg} / \mathrm{s}$ hot water mass flow rate is $9488 \$ / \mathrm{kW}$, while this value for the same ORC plant with $90{ }^{\circ} \mathrm{C}$ hot water temperature and $50 \mathrm{~kg} / \mathrm{s}$ hot water mass flow rate is $1869 \$ / \mathrm{kW}$. While the SIC value for existed geothermal ORC plants is varied from $1300 \$ / \mathrm{kWh}$ for a 1 MW plant to $5200 \$ / \mathrm{kWh}$ which was for an ORC plant with $4 \mathrm{MW}$ power generation capacity [55]. It can be concluded that springs with a higher temperature and water mass flow rate are more efficient economically.
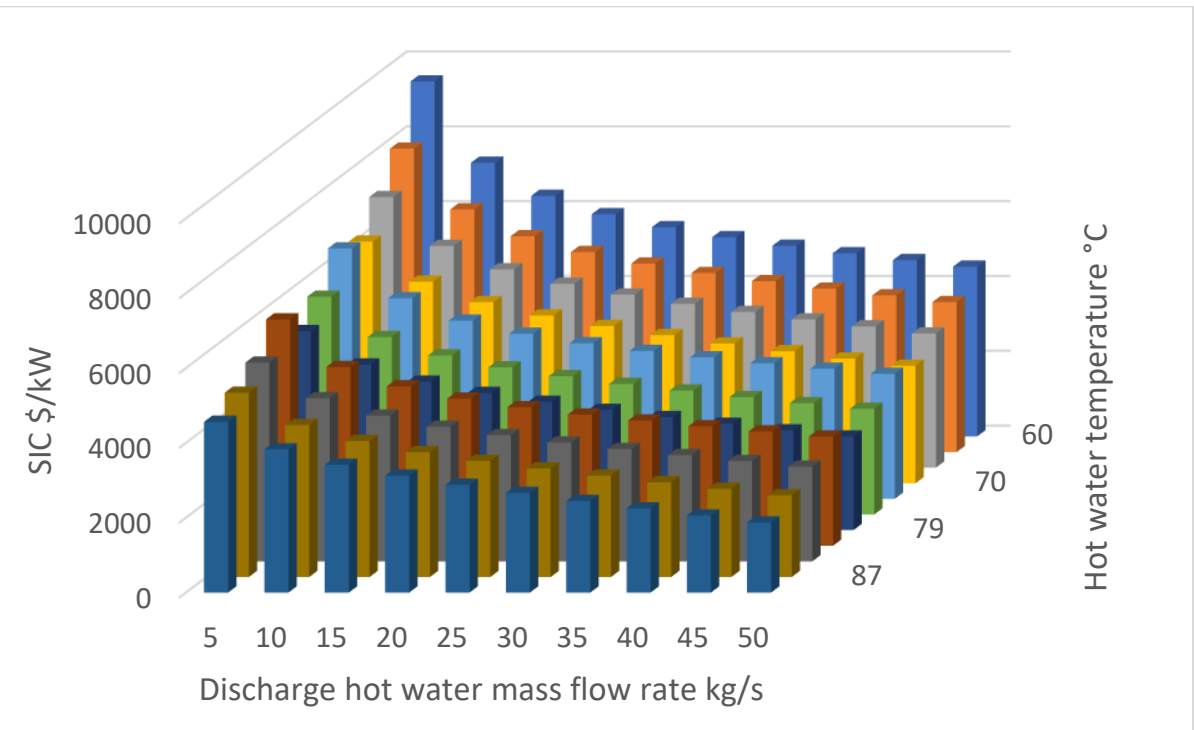

Figure 9: the SIC value for different hot springs 
The LEC for hot springs ORC energy plant with various water temperatures and discharge mass flow rates is shown in Figure 10. Figure 10 shows that LEC shrinks by increasing the hot spring discharge water mass flow. For example, in a hot spring with $90{ }^{\circ} \mathrm{C}$ temperature, the LEC decreases from $0.062 \$ / \mathrm{kWh}$ to 0.026 $\$ / \mathrm{kWh}$ when its water mass flow rate increases from $5 \mathrm{~kg} / \mathrm{s}$ to $50 \mathrm{~kg} / \mathrm{s}$. Also, reducing LEC value can be seen in Figure 10 by increasing the temperature of hot spring water. When a hot spring with a $50 \mathrm{~kg} / \mathrm{s}$ water mass flow rate is considered, by increasing the water temperature from $60{ }^{\circ} \mathrm{C}$ to $90{ }^{\circ} \mathrm{C}$, the LEC reduces from $0.062 \$ / \mathrm{kWh}$ to $0.026 \$ / \mathrm{kWh}$. Therefore, harnessing the energy of hot springs in an energy plant with higher water mass flow rate and temperature, reduce the LEC. While the average LEC for a geothermal plant is about $0.080 \$ / \mathrm{kWh}$ [56], exploiting from ORC in hot springs can reduce this value, especially in the springs with the higher temperature and mass flow rate. The improvement in LEC in some hot springs compared with deep-well geothermal power plant may be the result of excluding some cost in hot spring energy plant such as drilling cost.

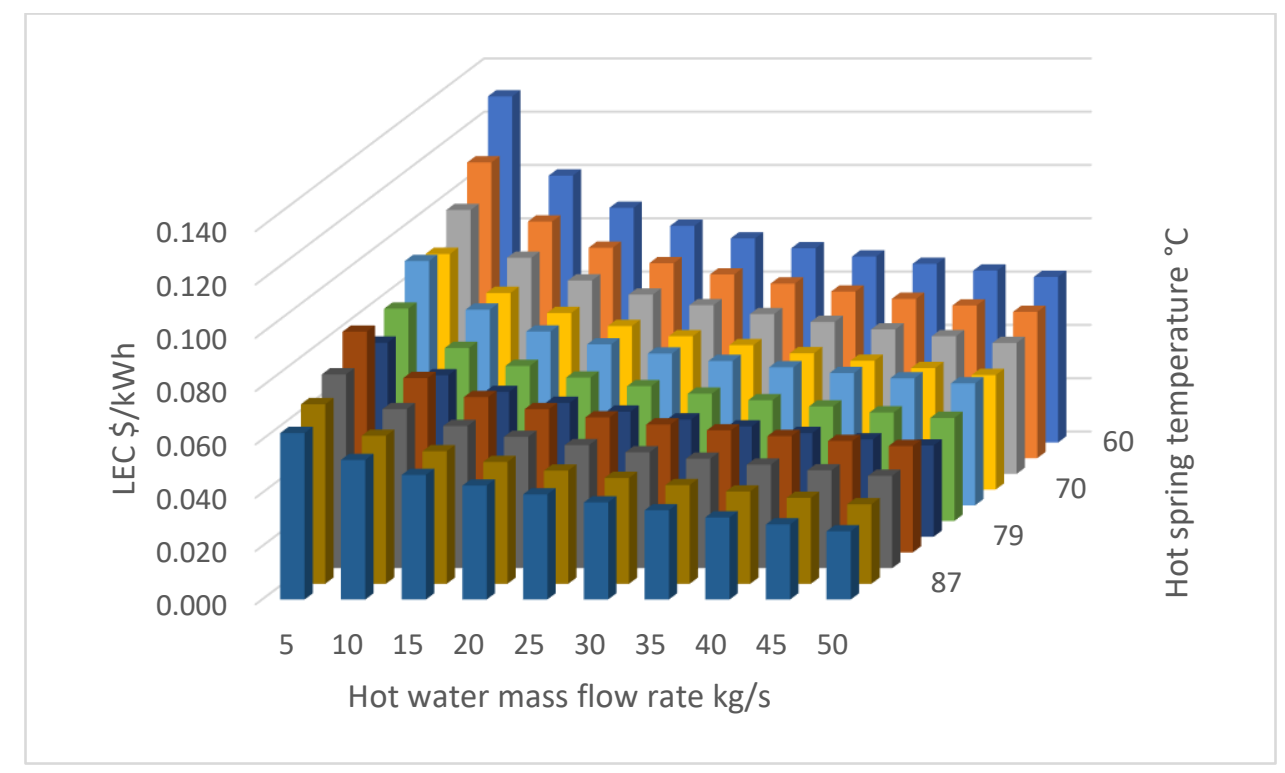

Figure 10: LEC value for hot springs with different mass flow rates and temperatures

The different IR in equations (14) and (15) affect the estimated LEC value in the same discharge mass flow rate of hot spring. To show the IR impact on LEC Figure 11 has been plotted with 4 values of IR 2\%, 3\%, $6 \%$, and $10 \%$ while the hot spring temperature was assumed $76{ }^{\circ} \mathrm{C}$, and the water mass flow rate was variable. The result show exhibits a non-linear correlation between IR and LEC value. Besides, increasing IR expands LEC value that makes the hot spring energy plant project less desirable economically. 


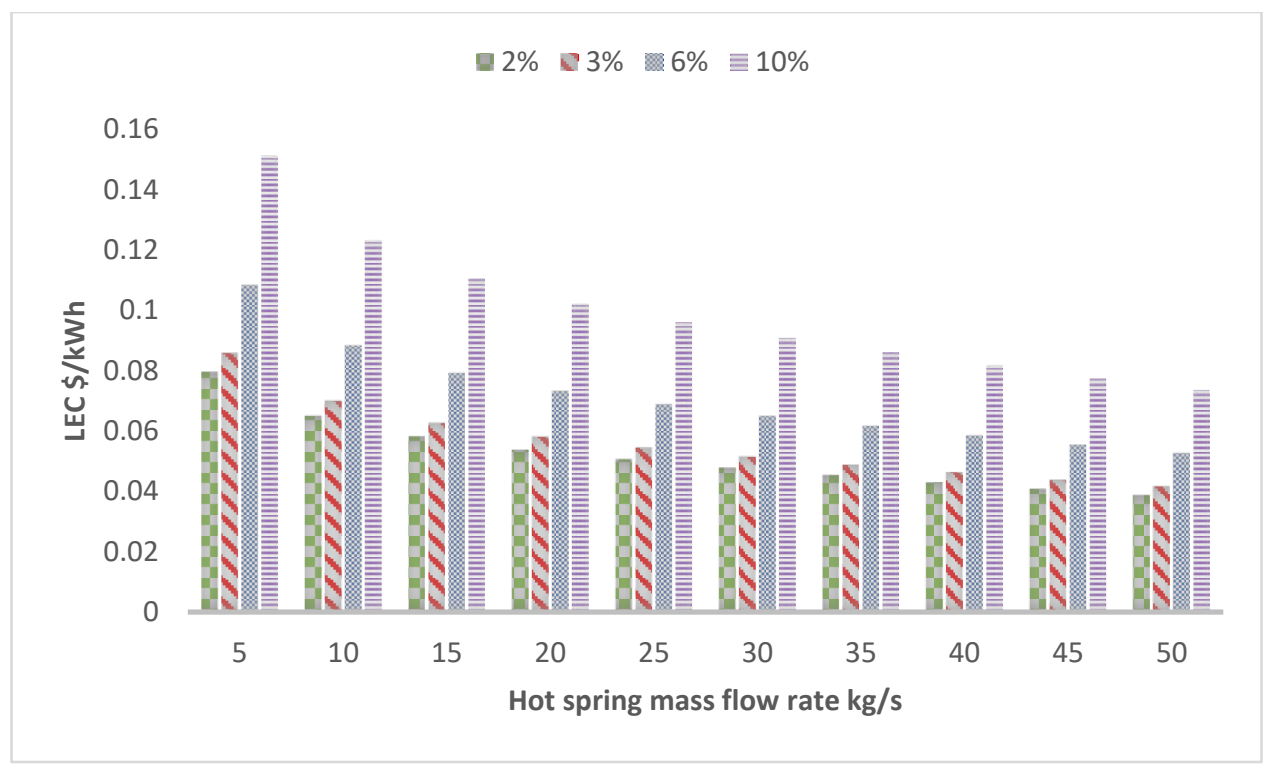

Figure 11: The impact of changing IR on the LEC

The impacts of the temperature and discharge mass flow rate of hot spring on the PP at an electricity cost of $0.10 \$ / \mathrm{kWh}$ is presented in Figure 12. The PP varies from 3.23 to 16.42 . The longest PP is estimated 16.42 years for a hot spring with $60{ }^{\circ} \mathrm{C}$ temperature and $5 \mathrm{~kg} / \mathrm{s}$ water discharge mass flowrate. The shortest PP is 3.42 years which is calculated for a hot spring with $90{ }^{\circ} \mathrm{C}$ temperature and $50 \mathrm{~kg} / \mathrm{s} \mathrm{discharge} \mathrm{mass}$ flow rate. Moreover, while the average PP for geothermal plants is 6 years [56], exploiting a hot spring energy plant may reduce this time in some cases. Figure 13 clarifies the range of temperature and discharge mass flowrate at which the PP of the energy plant can be more than 6 years.

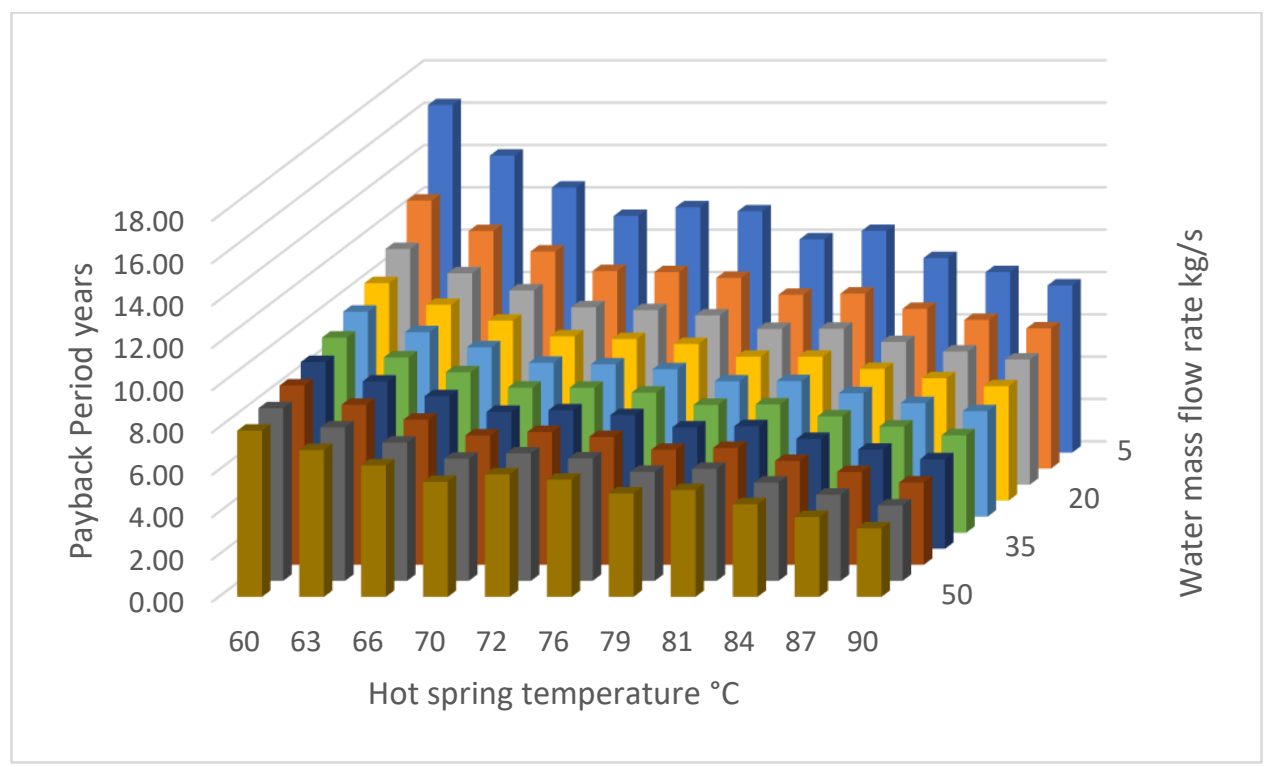

Figure 12: The impact of hot water temperature and mass flow rate on the Payback Period 


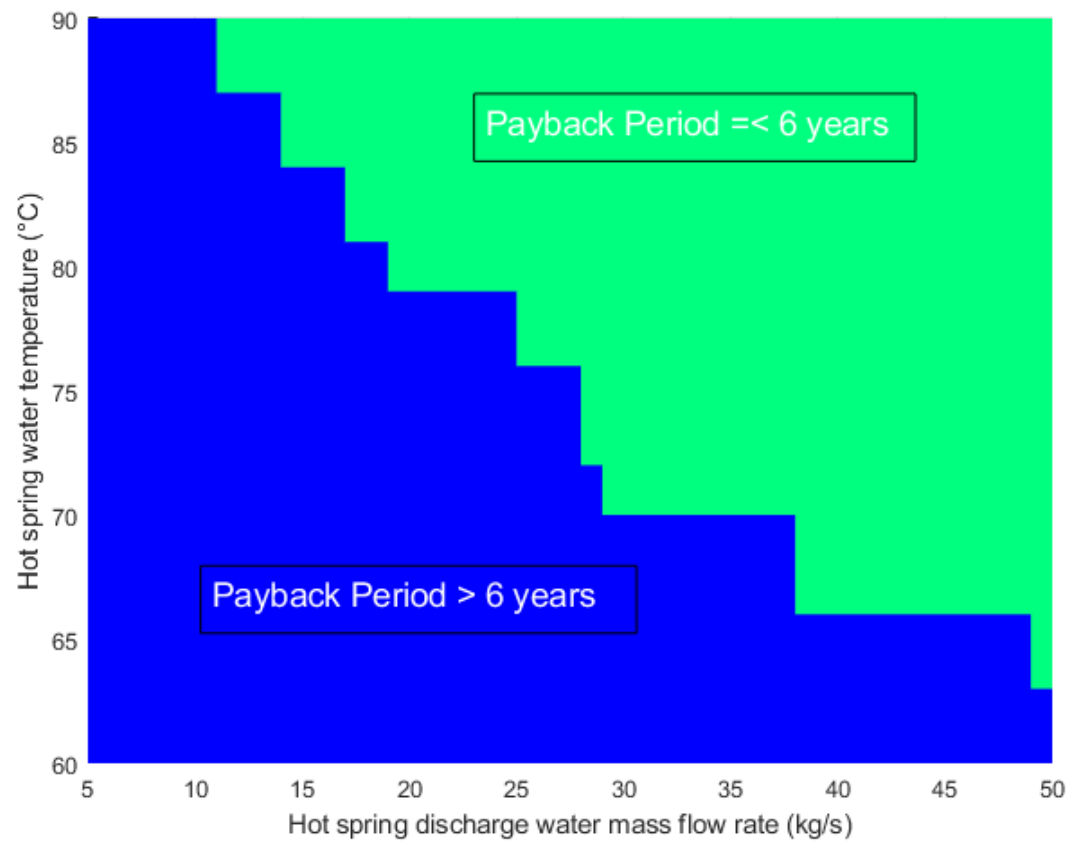

Figure 13: The energy plant PP in different hot spring temperature and water discharge mass flow rate

The electricity price varies based on location, for example in the US, this price is wide-ranging between 0.04 to $0.24 \$ / \mathrm{kWh}$. Figure 14 illustrates the electricity price impact on the PP of hot springs energy plant at discharge mass flow rate of $30 \mathrm{~kg} / \mathrm{s}$ with various temperatures of 60,76 , and $90{ }^{\circ} \mathrm{C}$. It can be observed that by increasing the price of electricity from 0.06 to $0.16 \$ / \mathrm{kWh}$, the PP shrinks to $6.02,3.94$, and 3.01 years for selected hot springs. Higher electricity price and higher temperature and mass flow rate of hot springs support the lower PP of the initial investment for the hot spring energy plants.

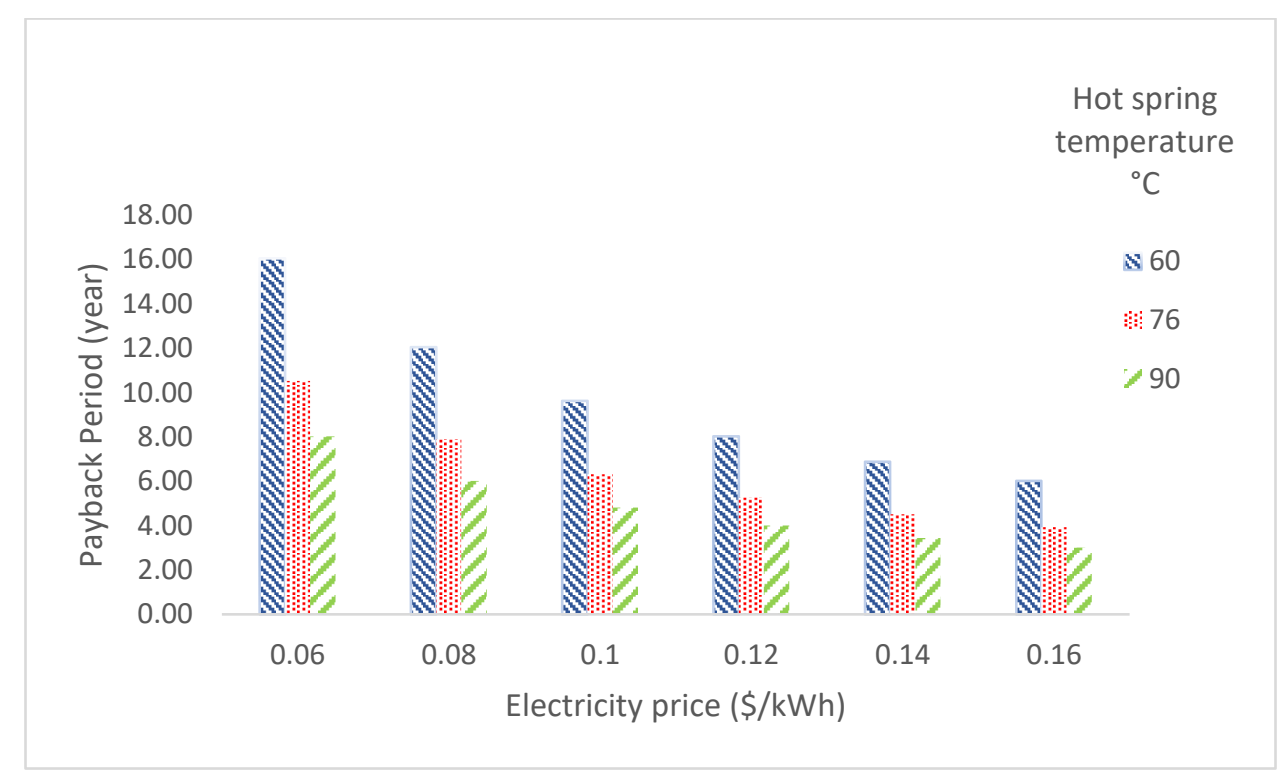

Figure 14: The impact of electricity price on the Payback Period 


\section{Conclusion}

Renewable power generation systems with low environmental impact are essential for a sustainable future. With the idea of improving the sustainability of the energy systems, this study focused on providing a guideline in harnessing an important low-temperature renewable energy source. Hot springs as natural energy storage system are dispersed throughout the world which can be used for power generation purposes as well as deep-well geothermal power plants. This paper has presented a guideline for harnessing power through various hot springs with different temperatures and discharge mass flow rates. The technical, economical, and environmental aspects of exploiting hot springs for power generation have been considered in this study.

In the technical analysis, ORC is found as the most suitable cycle for generating power in the hot spring which is a low-temperature energy source. A thermodynamic model of the power generation cycle was modeled and simulated in Aspen Plus V9. Hot spring temperature and discharge mass flow rate is found as essential parameters in finding power generation rate in an energy plant. By increasing the hot spring temperature from $60{ }^{\circ} \mathrm{C}$ to $90{ }^{\circ} \mathrm{C}$ and its discharge mass flow rate from 5 to $50 \mathrm{~kg} / \mathrm{s}$, its power generation capacity enhances from $9.3 \mathrm{~kW}$ to $303 \mathrm{~kW}$ and its thermal efficiency improves from $4.2 \%$ to $7.2 \%$.

The economic model of the different hot spring energy plants has been developed in this study. Developing an economic model has been done using actual cost quotes from US suppliers. The SIC value of the hot spring energy plant can be reduced from $9488 \$ / \mathrm{kWh}$ to $1869 \$ / \mathrm{kWh}$ by increasing hot spring temperature and discharge mass flow rate. Analyzing PP demonstrates that by increasing the temperature and discharge mass flow rate of hot springs, the PP decreases from 16.3 years to 3.3 years. Also, PP analysis shows the cost-effectiveness of hot springs energy plants based on their temperature and discharge mass flow rate (Figure 13) which can be a guideline for investing purposes.

The environmental impact of a power generation system is a concern for a sustainable future. Exploiting from natural energy storage with natural and permanent eruption will reduce the risk of geological changes. This is recognized as one important disadvantage of deep-well and large-scale geothermal power plants. Also, harnessing power from an air-medium heat exchanger instead of the water-medium condenser in the ORC will reduce the water consumption in geothermal plants. Also, exploiting this renewable energy source will significantly reduce GHG emissions, especially when that is compared with fossil fuel power plants. The effect of this factor can be quantified economically by using carbon tax and tax benefit tools, presented in this study, based on countries' environmental regulations.

\section{Acknowledgment}

The authors would like to appreciate the Mechanical Engineering department of the University of Idaho for financial support. The authors also would like to appreciate Dr. Michael McKellar for assisting us with the Aspen Plus software.

\section{References}

[1] Harjanne A, Korhonen JM. Abandoning the concept of renewable energy. Energy Policy 2019;127:330-40. https://doi.org/10.1016/j.enpol.2018.12.029.

[2] Renewable power - Tracking Power - Analysis - IEA n.d. https://www.iea.org/reports/trackingpower-2019/renewable-power (accessed March 5, 2020).

[3] Tsai S-B, Xue Y, Zhang J, Chen Q, Liu Y, Zhou J, et al. Models for forecasting growth trends in renewable energy 2016. https://doi.org/10.1016/j.rser.2016.06.001. 
[4] Idrus Alhamid M, Daud Y, Surachman A, Sugiyono A, Aditya H, Mahlia T. Potential of geothermal energy for electricity generation in Indonesia: A review. Renew Sustain Energy Rev 2015;53:733-40. https://doi.org/10.1016/j.rser.2015.09.032.

[5] BP. Full report - BP Statistical Review of World Energy 2019. n.d.

[6] Anderson A, Rezaie B. Geothermal technology: Trends and potential role in a sustainable future. Appl Energy 2019;248:18-34. https://doi.org/10.1016/j.apenergy.2019.04.102.

[7] Dipippo R. Geothermal Power Plants: Principles, Applications and Case Studies and Environmental Impact. 2012.

[8] Tomasini-Montenegro C, Santoyo-Castelazo E, Gujba H, Romero RJ, Santoyo E. Life cycle assessment of geothermal power generation technologies: An updated review 2016. https://doi.org/10.1016/j.applthermaleng.2016.10.074.

[9] Bertani R. Geothermal power generation in the world 2010-2014 update report. Geothermics 2016;60:31-43. https://doi.org/10.1016/j.geothermics.2015.11.003.

[10] Barbier E. Geothermal energy technology and current status: An overview. Renew Sustain Energy Rev 2002;6:3-65. https://doi.org/10.1016/S1364-0321(02)00002-3.

[11] Watts-Henwood N, Campbell KA, Lynne BY, Guido DM, Rowland J V., Browne PRL. Snapshot of hot-spring sinter at Geyser Valley, Wairakei, New Zealand, following anthropogenic drawdown of the geothermal reservoir. Geothermics 2017;68:94-114. https://doi.org/10.1016/j.geothermics.2017.03.002.

[12] Noorollahi Y, Yousefi H, Itoi R, Ehara S. Geothermal energy resources and development in Iran. Renew Sustain Energy Rev 2009;13:1127-32. https://doi.org/10.1016/j.rser.2008.05.004.

[13] Baral S. Experimental and Techno-Economic Analysis of Solar-Geothermal Organic Rankine Cycle Technology for Power Generation in Nepal. Int J Photoenergy 2019. https://doi.org/10.1155/2019/5814265.

[14] Holdmann G. The Chena Hot Springs 400kW Geothermal Power Plant: Experience Gained During the First Year of Operation. Fairbanks, Alaska : 2007.

[15] Bhatia SC. Geothermal power generation. Adv. Renew. Energy Syst., Elsevier; 2014, p. 334-88. https://doi.org/10.1016/B978-1-78242-269-3.50014-0.

[16] Pentecost A, Jones B, Renaut RW. What is a hot spring? Can J Earth Sci 2003;40:1443-6. https://doi.org/10.1139/e03-083.

[17] Berry GW, Grim PJ, Ikelman JA. Thermal Springs List for the United States. 1980.

[18] Liao Z. Thermal Springs in China, Springer, Singapore; 2018, p. 5-11. https://doi.org/10.1007/978-981-10-3485-5_2.

[19] Sun J, Liu Q, Duan Y. Effects of evaporator pinch point temperature difference on thermoeconomic performance of geothermal organic Rankine cycle systems. Geothermics 2018;75:24958. https://doi.org/10.1016/j.geothermics.2018.06.001.

[20] Gaucher E, Schoenball M, Heidbach O, Zang A, Fokker PA, Van Wees JD, et al. Induced seismicity in geothermal reservoirs: A review of forecasting approaches. Renew Sustain Energy Rev 2015;52:1473-90. https://doi.org/10.1016/j.rser.2015.08.026.

[21] Madhawa Hettiarachchi HD, Golubovic M, Worek WM, Ikegami Y. Optimum design criteria for 
an Organic Rankine cycle using low-temperature geothermal heat sources. Energy 2007;32:1698706. https://doi.org/10.1016/j.energy.2007.01.005.

[22] Yamamoto T, Furuhata T, Arai N, Mori K. Design and testing of the Organic Rankine Cycle. vol. 26. 2001.

[23] Navarro-Esbrí J, Amat-Albuixech M, Molés F, Mateu-Royo C, Mota-Babiloni A, Collado R. HCFO-1224yd(Z) as HFC-245fa drop-in alternative in low temperature ORC systems: Experimental analysis in a waste heat recovery real facility. Energy 2020;193:116701. https://doi.org/10.1016/j.energy.2019.116701.

[24] Petrollese M, Cau G, Cocco D. The Ottana solar facility: dispatchable power from small-scale CSP plants based on ORC systems. Renew Energy 2020;147:2932-43. https://doi.org/10.1016/j.renene.2018.07.013.

[25] Astolfi M, La Diega LN, Romano MC, Merlo U, Filippini S, Macchi E. Techno-economic optimization of a geothermal ORC with novel "Emeritus" heat rejection units in hot climates. Renew Energy 2020;147:2810-21. https://doi.org/10.1016/j.renene.2019.01.065.

[26] Kalina J, Świerzewski M, Strzałka R. Operational experiences of municipal heating plants with biomass-fired ORC cogeneration units. Energy Convers Manag 2019;181:544-61. https://doi.org/10.1016/j.enconman.2018.12.045.

[27] Quoilin S, Van Den Broek M, Bastien Declaye S, Dewallef P, Lemort V. Techno-economic survey of Organic Rankine Cycle (ORC) systems. Renew Sustain Energy Rev 2013;22:168-86. https://doi.org/10.1016/j.rser.2013.01.028.

[28] Saleh B, Koglbauer G, Wendland M, Fischer J. Working fluids for low-temperature organic Rankine cycles. Energy 2007;32:1210-21. https://doi.org/10.1016/j.energy.2006.07.001.

[29] Aghahosseini S, Dincer I. Comparative performance analysis of low-temperature Organic Rankine Cycle (ORC) using pure and zeotropic working fluids. Appl Therm Eng 2013;54:35-42. https://doi.org/10.1016/j.applthermaleng.2013.01.028.

[30] Tchanche BF, Lambrinos G, Frangoudakis A, Papadakis G. Low-grade heat conversion into power using organic Rankine cycles â $€$ "A review of various applications. Renew Sustain Energy Rev 2011;15:3963-79. https://doi.org/10.1016/j.rser.2011.07.024.

[31] Rahbar K, Mahmoud S, Al-Dadah RK, Moazami N, Mirhadizadeh SA. Review of organic Rankine cycle for small-scale applications. Energy Convers Manag 2017;134:135-55. https://doi.org/10.1016/j.enconman.2016.12.023.

[32] Walraven D, Laenen B, D'haeseleer W. Economic system optimization of air-cooled organic Rankine cycles powered by low-temperature geothermal heat sources. Energy 2015;80:104-13. https://doi.org/10.1016/j.energy.2014.11.048.

[33] Cleveland CJ, Morris C. Geothermal. Handb. Energy, Elsevier; 2014, p. 303-7. https://doi.org/10.1016/B978-0-12-417013-1.00016-9.

[34] Andrić I, Pina A, Ferrão P, Fournier J, Lacarrière B, Le Corre O, et al. A World Overview of the Organic Rankine Cycle Market ScienceDirect A World Overview of the Organic Rankine Cycle Market. Energy Procedia 2017;129:2-9. https://doi.org/10.1016/j.egypro.2017.09.159.

[35] Budisulistyo D. Feasibility Analysis of ORC Systems: Thermo-Economic and Technical Considerations for Flexible Design. University of Canterbury , 2016. 
[36] Bejan A. Advanced engineering thermodynamics. 2016.

[37] Rezaie B, Reddy B V., Rosen MA. An enviro-economic function for assessing energy resources for district energy systems. Energy 2014;70:159-64. https://doi.org/10.1016/j.energy.2014.03.101.

[38] Imran M, Park BS, Kim HJ, Lee DH, Usman M, Heo M. Thermo-economic optimization of Regenerative Organic Rankine Cycle for waste heat recovery applications. Energy Convers Manag 2014;87:107-18. https://doi.org/10.1016/j.enconman.2014.06.091.

[39] Penoncello S. Thermal energy systems: design and analysis. 2018.

[40] Nafey AS, Sharaf MA. Combined solar organic Rankine cycle with reverse osmosis desalination process: Energy, exergy, and cost evaluations. Renew Energy 2010;35:2571-80. https://doi.org/10.1016/j.renene.2010.03.034.

[41] Wang XQ, Li XP, Li YR, Wu CM. Payback period estimation and parameter optimization of subcritical organic Rankine cycle system for waste heat recovery. Energy 2015;88:734-45. https://doi.org/10.1016/j.energy.2015.05.095.

[42] Heberle F, Brüggemann D. Exergy based fluid selection for a geothermal Organic Rankine Cycle for combined heat and power generation. Appl Therm Eng 2010;30:1326-32. https://doi.org/10.1016/j.applthermaleng.2010.02.012.

[43] Borsukiewicz-Gozdur A, Nowak W. Comparative analysis of natural and synthetic refrigerants in application to low temperature Clausius-Rankine cycle. Energy 2007;32:344-52. https://doi.org/10.1016/j.energy.2006.07.012.

[44] Nowak W, Borsukiewicz-Gozdur A, Stachel A, Klonowicz P, Hanausek P, Klonowicz W. Small prototype of ORC power plant fuelled by water at $100 \mathrm{C}$ : first experimental results. Przegl ${ }^{1} \mathrm{~d}$ Geol 2010;58:622-5.

[45] Borsukiewicz-Gozdur A. Experimental investigation of R227ea applied as working fluid in the ORC power plant with hermetic turbogenerator. Appl Therm Eng 2013;56:126-33. https://doi.org/10.1016/j.applthermaleng.2013.03.039.

[46] Pikra G, Rohmah N, Indra Pramana R, Purwanto AJ. The electricity power potency estimation from hot spring in Indonesia with temperature $70-80^{\circ} \mathrm{C}$ using organic Rankine cycle. Energy Procedia 2015;68:12-21. https://doi.org/10.1016/j.egypro.2015.03.227.

[47] Wang D, Ling X, Peng H, Liu L, Tao LL. Efficiency and optimal performance evaluation of organic Rankine cycle for low grade waste heat power generation. Energy 2013;50:343-52. https://doi.org/10.1016/j.energy.2012.11.010.

[48] Lin J, Qin G, Yue H. Optimization of binary zeotropic mixture working fluids for an organic Rankine cycle for waste heat recovery between centrifugal compressor stages. Energy Sci Eng 2020;8:1746-57. https://doi.org/10.1002/ese3.629.

[49] Shokati N, Ranjbar F, Yari M. Exergoeconomic analysis and optimization of basic, dual-pressure and dual-fluid ORCs and Kalina geothermal power plants: A comparative study. Renew Energy 2015;83:527-42. https://doi.org/10.1016/j.renene.2015.04.069.

[50] Wong KV, Tan N. Feasibility of using more geothermal energy to generate electricity. J Energy Resour Technol Trans ASME 2015;137. https://doi.org/10.1115/1.4028138.

[51] Shengjun Z, Huaixin W, Tao G. Performance comparison and parametric optimization of subcritical Organic Rankine Cycle (ORC) and transcritical power cycle system for low- 
temperature geothermal power generation. Appl Energy 2011;88:2740-54.

https://doi.org/10.1016/j.apenergy.2011.02.034.

[52] Lecompte S, Lemmens S, Huisseune H, van den Broek M, De Paepe M. Multi-Objective ThermoEconomic Optimization Strategy for ORCs Applied to Subcritical and Transcritical Cycles for Waste Heat Recovery. Energies 2015;8:2714-41. https://doi.org/10.3390/en8042714.

[53] Electric Power Monthly - U.S. Energy Information Administration (EIA) n.d. https://www.eia.gov/electricity/monthly/epm_table_grapher.php?t=epmt_5_6_a (accessed August $17,2020)$.

[54] Rezaie B, Reddy B V, Rosen MA. Economic and CO 2 Emissions Comparison of District Energy Systems using Geothermal and Solar Energy Resources. 3rd Word Sustain. Forum, 2013.

[55] Lemmens S. Cost Engineering Techniques and Their Applicability for Cost Estimation of Organic Rankine Cycle Systems. Energies 2016;9:485. https://doi.org/10.3390/en9070485.

[56] Li K, Bian H, Liu C, Zhang D, Yang Y. Comparison of geothermal with solar and wind power generation systems. Renew Sustain Energy Rev 2015;42:1464-74.

https://doi.org/10.1016/j.rser.2014.10.049. 